рослин», присвяченої 260-річчю виходу праці К. Ростов-на-Дону: Издательство Южного Федерального Ліннея «Species plantarum», 115-річчю відкриття подівійного запліднення С.Г. Навашиним і 60-річчю створення моделі структури ДНК Д. Уотсоном і Ф. Криком (Україна, Луганськ, 03-07 червня 2013 р.) // Ред. І.Д. Соколов. Луганськ: Елтон-2, 2013. С. 16-18.

24. Остапко В.М., Приходько С.А. Фиторазнообразие юго-востока Украины и перспективы его сохранения // Роль ботанических садов в сохранении и мониторинге биоразнообразия: сборник материалов / отв. ред. Т.В. Вардуни, П.А. Дмитриев, О.А. Капралова.

университета, 2015. С. 243-246.

25. Бурда Р.И. Антропогенная трансформация флоры. Киев: Наук. думка, 1991. 168 с.

26. Донбас заповідний. Науково-інформаційний довідник-атлас / Під заг. ред. С.С. Куруленка, С.В. Третьякова. Донецьк: ДФ ДІПКПК Мінекоресурсів України, 2003. 160 с.

27. Зелена книга України / Під. ред. чл.-кор. Я.П. Дідуха. К.: Альтпрес, 2009. 448 с.

\title{
SYNPHYTOSOZOLOGICAL ASSESSMENT OF PASTURE ECOSYSTEMS VEGETATION IN SOUTH-EAST UKRAINE
}

(C) 2016

V.M. Ostapko, doctor of biological sciences, professor,

head of Natural Flora and Nature Conservation Department, deputy director for scientific work Donetsk Botanical Garden, Donetsk (Donetsk People's Republic)

O.M. Shevchuk, doctor of biological sciences, head of Aromatic and Medicinal Plants Laboratory

Nikita Botanical Garden - National Research Center of Russian Academy of Sciences, Yalta, u.t.s. Nikita (Russia)

S.A. Prikhodko, candidate of biological sciences,

head of Phytoecology Department, director

Donetsk Botanical Garden, Donetsk (Donetsk People's Republic)

Abstract. As part of the pasture vegetation of steppe ecosystems of the south-east of Ukraine we found 62 rarity formations (79\% of the total number), with $338(52 \%)$ rarity associations of dominant classification. Green Book of Ukraine includes 18 formations with 79 associations (respectively, 54\% and 67\% of these syntaxa of regional vegetation), and the rest of the formations and associations are rare for this region. Rare vegetation formations and their associations are listed and distributed by types of grassland steppe ecosystems. The highest syntaxonomic variety is characteristic for gully and ravine steppe ecosystems formed on eroded chernozems underlain by loess ( 750 associations of 81 formations), the least syntaxonomic diversity is found in above-floodplain terraced steppes on the sands (140 associations of 24 formations). The greatest number of regionally rare associations is cenotically confined to the chalk outcrops (49 associations of 16 formations). A large number of associations are stenotopic. These results suggest a high synphytosozological value of pasture ecosystems vegetation in the south-east of Ukraine, which is very important for the conservation of the steppe biome biodiversity. It should be taken into account when grounding establishment of the local reserves for biota protection, their protection regimes and performing pasture load calculations for specific areas.

Keywords: synphytosozology; rare formation; rare association; steppe ecosystem; grassland ecosystem; south-east of Ukraine; Green Book; vegetation; syntaxonomic variety; phytocenotic diversity; watershed ecosystem; ravine-gully ecosystem; above-flood plain terraced ecosystem.

УДК 598.2

\section{ВЛИЯНИЕ СОВРЕМЕННЫХ ПРЕОБРАЗОВАНИЙ ИНФРАСТРУКТУРЫ ГОРОДА САМАРЫ НА БИОЛОГИЮ ГНЕЗДОВАНИЯ ЯСТРЕБА-ПЕРЕПЕЛЯТНИКА} (C) 2016

\author{
И.С. Павлов, кандидат биологических наук, заместитель председателя \\ Самарское отделение Союза охраны птии России, Самара (Россия) \\ В.Н. Макаренков, преподаватель \\ Детская художественная школа № 2, Самара (Россия)
}

\begin{abstract}
Аннотация. На основании наблюдений с 1997 г. за соколообразными птицами, обитающими на территории города Самары, было выявлено, что наиболее многочисленным и широко распространенным пернатым хищником в данных условиях оказался ястреб-перепелятник. За этот период численность данного вида в указанном районе росла. В настоящее время она оценивается нами более чем в 50 пар. В условиях города большинство ястребов населяют типичные для них стации - лесные массивы, с большой долей молодых деревьев, как естественные, так и посадки, с площадью от 1 га. При этом в последние 5-7 лет наметилась тенденция к гнездованию ястребов в нетипичных для них очень малых по площади насаждениях в густонаселенных районах города. В 2016 г. нами было обнаружено гнездо перепелятников на пустыре практически в географическом центре Самары площадью не более 0,5 га, в 50 м от дороги и буквально в 5 м от тропы. При этом ястребам удалось успешно вырастить выводок - из гнезда вылетело 3 слетка (2 самки и 1 самец). Таким образом, несмотря на активное окультуривание и освоение лесопарковых зон и пустырей в городе Самара, осуществляемых в последние годы, перепелятники, находя здесь, в первую очередь, оптимальные кормовые условия, проявляют практически весь адаптационный потенциал для приспособления к меняющимся условиям.
\end{abstract}


Ключевые слова: перепелятник; ястреб; город Самара; городская популяция; численность; распределение; гнездование; антропогенное воздействие; фактор беспокойства; современные тенденции; проявления адаптации; нетипичные местообитания; стабильная кормовая база; оптимальные условия; лимитирующие факторы; приспособления; успешность гнездования.

Известно, что многие виды соколообразных птиц, обладая значительной пластичностью, проявляют достаточную степень толерантности по отношению к антропогенному воздействию, включая непосредственное соседство с человеком. Это в существенной мере позволяет им занимать пустующие по большей части хищнические ниши в экосистемах урбоценозов [1-5].

Город Самара, несмотря на численность населения и значительную степень развития инфраструктуры, в отношении представленности гнездящихся хищных птиц, представляет собой яркий пример достаточной привлекательности для обитания последних, особенно в постсоветский период.

На основании собственных наблюдений за почти двадцатилетний период (начиная с 1997 г.) в административных границах Самары было доказано гнездование 14 видов соколообразных птиц, 7 из которых регулярно отмечаются на обитании в непосредственной близости от человеческого жилья. Это - перепелятник, чеглок, черный коршун, болотный лунь, обыкновенный канюк, обыкновенная пустельга и тетеревятник (виды перечислены здесь в порядке убывания их численности в городе) [6-9].

При этом за все время наблюдений можно констатировать, что численность «самарских популяций» некоторых из перечисленных хищников снижается (пустельга, кобчик), у некоторых наблюдается существенный рост и активное заселение новых территорий (перепелятник, чеглок, орел-карлик), у остальных же - заметная стабильность, в отличие даже от популяций, обитающих в естественных биотопах. Это можно объяснить рядом причин, основные из которых - отсутствие прямого преследования со стороны человека (при условии «малозаметности» пернатых хищников), низкий уровень конкуренции (как пищевой, так и гнездовой, за гнездовой субстрат), обильность и постоянство кормовой базы, в особенности для орнитофагов (перепелятник, чеглок, тетеревятник), что обусловлено также значительным ростом количества мелких воробьинообразных птиц, наблюдаемым после прекращения массовых систематических обработок городских и пригородных территорий инсектицидами, проводившимися в советский период.

Таким образом, по нашим оценкам, перепелятник является самым многочисленным представителем соколообразных птиц, гнездящихся в административных границах города Самары. Его относительная численность составляет на указанной территории не менее 50 гнездящихся пар.

Типичным местообитанием этого ястреба являются молодые лесные массивы, в том числе и небольшие рощи, спелые высокоствольные леса с развитым подлеском, достаточно широкие и густые лесопосадки (не менее 5-7 «полос» деревьев), как хвойные, так и смешанные, и лиственные. Не избегает он и пойменных лесов, хотя встречается в них гораздо реже [1, 10-14]. Таким образом, в связи со значительной облесенностью промзон и окраин города Самары, а также значительной численностью мелких воробьинообразных птиц (основных видов-жертв), как уже говорилось выше, этот пернатый хищник находит здесь для себя вполне комфортные условия для обитания.
Благодаря последнему указанному выше фактору и низкому уровню конкуренции, а также из-за существенной пластичности вида к беспокойству в гнездовой период, перепелятник за последние 10-15 лет в значительной степени освоил и довольно населенные районы полуторамиллионного города. Так, к 1999 г. он стал ежегодно гнездиться в ботаническом саду и парке Молодежном. В середине 2000-х гг. нами зарегистрировано регулярное гнездование ястребов в парке Дружбы, Загородном парке, зеленой зоне клиник Медуниверситета и заросших пустырях на месте железной дороги вдоль улицы Карла Маркса, где ранее вид либо отмечался периодически, либо вовсе не наблюдался.

В последние 5-7 лет в «самарской популяции» вида наметилась явная тенденция к занятию нетипичных гнездовых стаций в очень густонаселенных районах с высоким уровнем беспокойства со стороны человека. Из таковых можно привести в пример рощи на территории Областной детской инфекционной больницы и завода им. Тарасова, пустыри по улице Карбышева между улицами Дыбенко и АнтоноваОвсеенко и на пересечении улиц Димитрова и СтараЗагоры. В указанных случаях, как и в ряде других, ястреба выбирали для гнездования очень небольшие по площади рощи (не более 1-1,5 га), вблизи оживленных улиц, достаточно часто посещаемые людьми.

Последним, самым ярким примером, указанной тенденции можно считать обнаруженное нами в июле 2016 г. гнездо перепелятников, располагавшееся на пустыре по улице Карбышева в районе пересечения с улицей Блюхера. Гнездовая постройка выявлена в роще площадью не более 0,5 га, примерно в 50 метрах от проезжей части и буквально в 5 метрах от пешеходной тропы. Она располагалась на основном стволе американского клена на высоте всего 6-7 метров от земли. Постройка - типичная для данного вида: небольшая, достаточно рыхлая, в диаметре не превышающая $40 \mathrm{~cm}$ (рис. 1).

Точное количество птенцов в гнезде нам определить не удалось, т.к. подъем в гнездо было решено не производить, чтобы не рисковать самой постройкой и выводком в ней (она располагалась на молодом дереве с наклонным стволом, толщина которого у земли не превышала 15 cм, т.е. могло не выдержать веса человека), а также не привлекать внимания посторонних людей и не демаскировать его. Все же гнездование хищников в подобных условиях, в целом, мы склонны считать успешным (рис. 2, 3). В августе из гнезда вылетели 3 слетка (2 самки и 1 самец) (рис. 4, 5), хотя при оптимальных условиях в Среднем Поволжье размер выводка данных ястребов составляет 4-5 слетков $[1,11-14]$.

Еще из специфических особенностей наблюдаемой пары следует отметить их достаточную «молчаливость» и относительно низкую активность при защите гнездовой территории. Для перепелятника, в целом, свойственна значительная вокализация у гнезда как взрослых птиц, так и слетков. Кроме того, большинство этих птиц очень активно защищают кладку и выводок от более крупных птиц (в том числе и серых 
Павлов И.С., Макаренков В.Н.

Влияние современных преобразований инфраструктуры города Самары

03.02.00 - общая биология

ворон) и наземных опасностей, вплоть до человека, начиная проявлять беспокойство иногда еще за 50-60 метров от опасного объекта [1, 10]. Молчаливость наблюдаемой нами пары во многом, видимо, и позволила птицам успешно вырастить выводок.

Кроме того, при исследовании пищевых остатков под гнездом перепелятников нами были обнаружены останки черного стрижа (рис. 6), который является

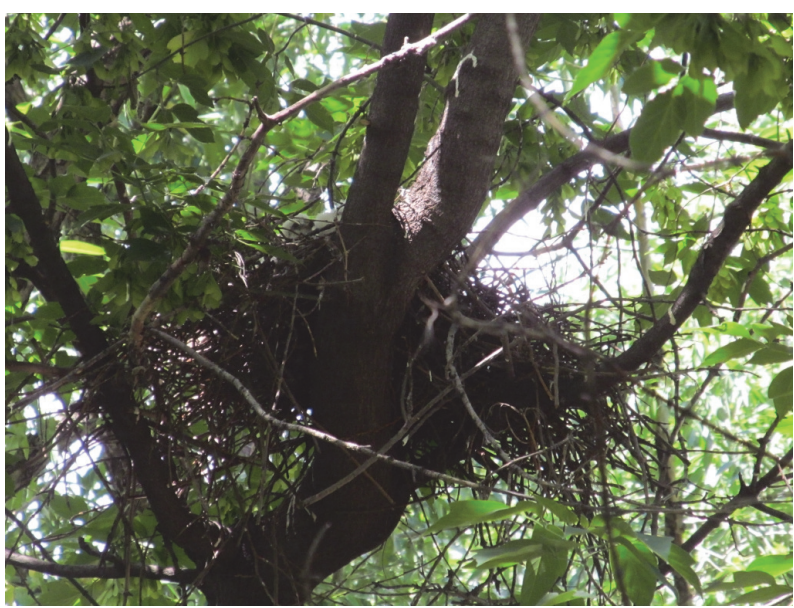

Рисунок 1 - Гнездо перепелятника.

Видны 2 птенца во втором пуховом наряде (фото В.Н. Макаренкова)

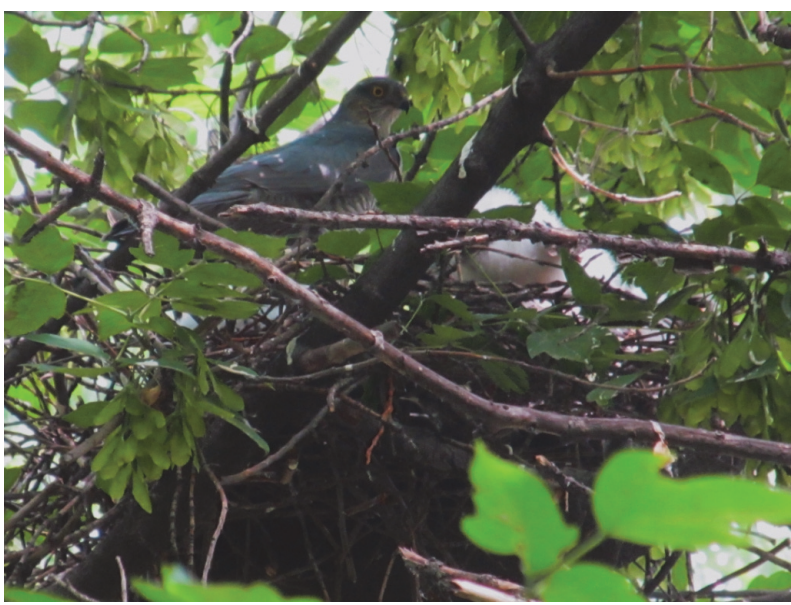

Рисунок 3 - Взрослая самка перепелятника на гнезде с птенцами. Процесс кормления (фото В.Н. Макаренкова)

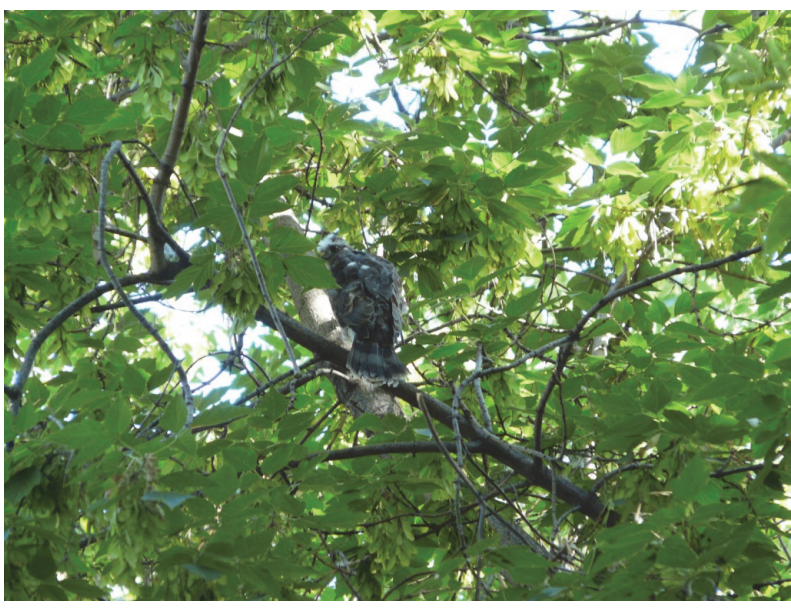

Рисунок 5 - Слетки в первое время после выхода из гнезда держатся в непосредственной близости от него. Молодой самец (фото И.С. Павлова) нетипичным кормовым объектом для ястребов и очень редко становится их добычей $[10,11,15,14]$. В то же время, стрижи при их высокой численности и повсеместном распространении составляют до 85$87 \%$ рациона чеглоков, обитающих в г. Самара, являясь как раз для этого хищника, с учетом его анатомических и поведенческих адаптаций, самой обычной пищей $[1,10,11,14]$.

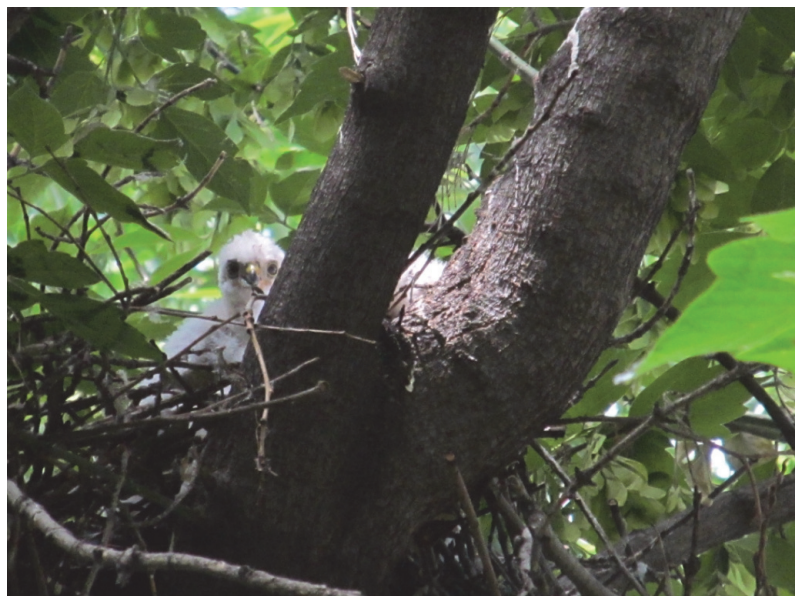

Рисунок 2 - 2 птенца в гнезде. Сквозь пух хорошо видны пробивающиеся более темные «пеньки» перьев (фото В.Н. Макаренкова)

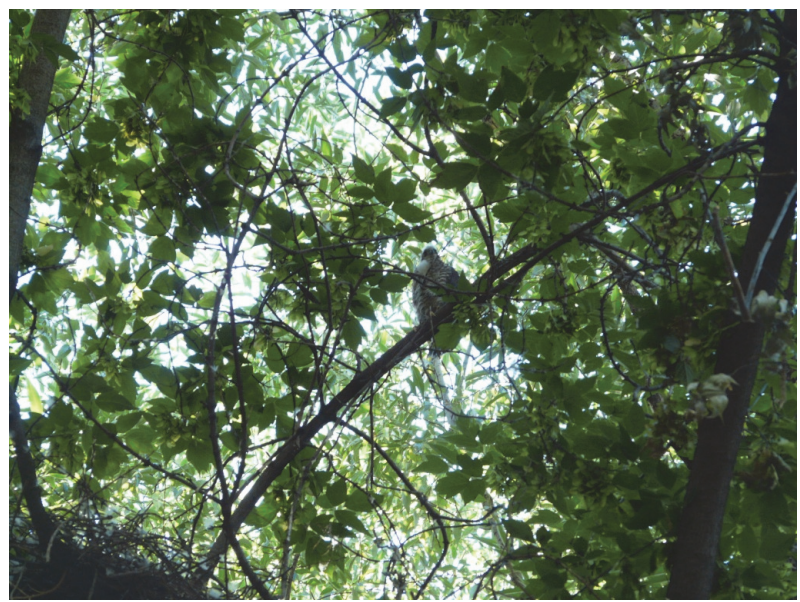

Рисунок 4 - Перепелятник-слеток покинул гнездо с еще не доросшим оперением. Молодая самка (фото И.С. Павлова)

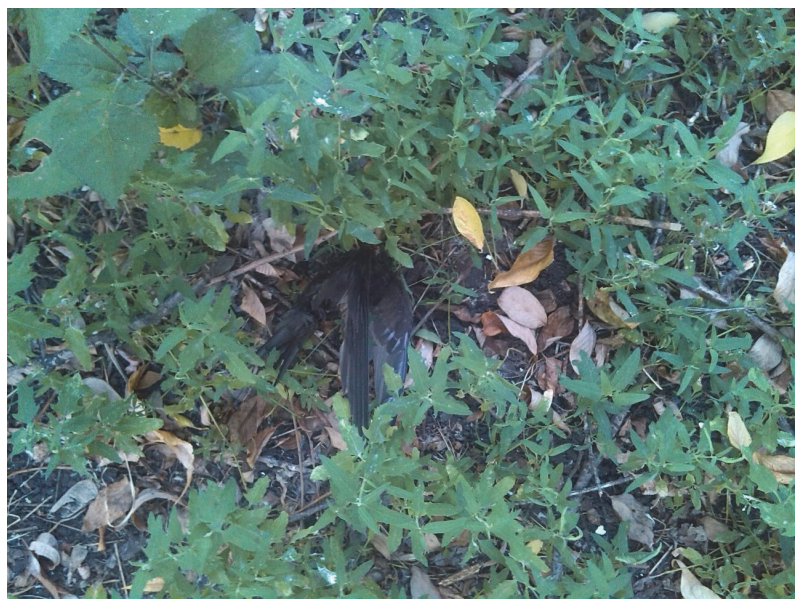

Рисунок 6 - Останки черного стрижа, обнаруженные под гнездом перепелятника. Обезглавленный труп молодой птицы (фото И.С. Павлова) 
Таким образом, из последних наших наблюдений за гнездящимися на территории г. Самары перепелятниками можно сделать следующее заключение:

1. В границах г. Самары, несмотря на существенную освоенность его территории, большую численность населения и высокую степень уровня фактора беспокойства, перепелятники находят для себя вполне оптимальные условия для гнездования в первую очередь за счет обильной и легко доступной кормовой базы. Именно благодаря этому, на наш взгляд, хищники в значительной степени проявляют весь потенциал толерантности и адаптивности к присутствующим здесь лимитирующим факторам.

2. Активно проводимые в последние годы администрацией городского округа работы по облагораживанию лесопарковых зон (расчистка от подлеска и реконструкция парков и скверов, ликвидация «спонтанных» зарослей), застройка либо окультуривание пустырей в большой мере сокращает пригодные для гнездования ястребов территории, вынуждая их заселять незначительные древесные посадки и приспосабливаться к обитанию в новых условиях.

\section{СПИСОК ЛИТЕРАТУРЫ:}

1. Галушин В.М. Хищные птицы леса. М.: Лесная промышленность, 1980.

2. Галушин B.M. Адаптации хищных птиц к современным антропогенным воздействиям // Зоологический журнал. 1982. T. LXI. Вып. 7. C. 1088-1096.

3. Галушин В.М. Адаптация хищных птиц к меняющимся условиям среды // XVIII Международный орнитологический конгресс: Тезисы докладов и стендовых сообщений. М.: Наука, 1982. С. 35.

4. Галушин В.М. Особенности экопластики хищных птиц // Изучение и охрана хищных птиц Северной Евразии: мат-лы V междунар. конф. по хищным птицам Северной Евразии. Иваново: Иван. гос. ун-т, 2008. C. $80-82$.

5. Шепель А.И. Адаптации некоторых хищных птиц и сов к антропогенным воздействиям // Экология и поведение птиц: сб. науч. тр. М.: Наука, 1988. С. $180-189$.

6. Рахимов И.И. Дневные хищники и совы урбанизированных территорий Татарстана // Региональные эколого-фаунистические исследования как научная основа фаунистического мониторинга. Научно-практическая конференция: тез. докладов. Ульяновск: Изд. УлГПУ, 1995. С. 159-161.

7. Птицы городов Среднего Поволжья и Предуралья / под ред. И.И. Рахимова. Казань: Мастер Лайн, 2001.

8. Рахимов И.И. Дневные хищники в антропогенных ландшафтах Среднего Поволжья // Материалы IV конференции по хищным птицам Северной Евразии. Пенза: ПГПУ, 2003. С. 241-243.

9. Павлов И.С. Орнитологические находки в окрестностях города Самары // Исследования в области биологии и методики ее преподавания. Межвузовский сборник научных трудов. Вып. 3(1). Самара: СГПУ, 2003. C. $398-400$.

10. Штегман Б.К. Дневные хищники // Фауна СССР. Птицы. Т. І. Вып. 5. М.-Л.: Изд. АН СССР, 1937.

11. Дементьев Г.П. Отряд хищные птицы. // Птицы Советского Союза. Т. І. М.: Советская наука, 1951. C. $70-341$.

12. Птицы Волжско-Камского края. Неворобьиные / под ред. В.А. Попова. М.: Наука, 1977.

13. Рябицев В.К. Птицы Урала, Приуралья и Западной Сибири: Справочник-определитель. Екатеринбург: Изд. Урал. ун-та, 2001.

14. Павлов С.И., Павлов И.С. Хищные птицы Самарского края. Самара: Самарское отд. СОПР. Самара: СамНЦ РАН, 2008.

15. Белик В.П. Питание перепелятника в гнездовой период в Саратовском Поволжье // Изучение и охрана хищных птиц Северной Евразии: материалы V международной конференции по хищным птицам Северной Евразии. Иваново: Иван. гос. ун-т, 2008. С. 69-71.

\title{
THE IMPACT OF MODERN TRANSFORMATIONS OF THE INFRASTRUCTURE OF THE CITY OF SAMARA ON THE BREEDING BIOLOGY OF THE SPARROWHAWK
}

(C) 2016

\author{
I.S. Pavlov, candidate of biological sciences, deputy chairman \\ Samara branch of Russian Bird Conservation Union, Samara (Russia) \\ V.N. Makarenkov, teacher \\ Children Art School \# 2, Samara (Russia)
}

Abstract. Since 1997, we watched the birds of prey that lived in the Samara city, and found that the most numerous and widespread in these conditions is a Sparrow hawk. During this time, the number of this type birds of increase. Now it is we value it more than 50 pairs. In urban environments, many hawks inhabit the typical places for them - woodland area of more than 1 hectare, where a lot of young trees. Not only the natural forests but artificial too. In the last 5-7 years there has been a tendency to breed hawks in atypical for their groves with a very small area in the densely populated areas of the city. In 2016, we found Sparrow hawk's nest in a grove near the geographical center of the Samara city. Area trees no more than 0,5 hectares, it is 50 meters from the road, and 5 meters from the curb. But here the hawks successfully grow brood. 3 young hawks are haking in the and of nesting ( 2 females and 1 male). Thus, despite the active cultivation and development of forest parks and vacant lots in the Samara city, carried out in recent years, sparrow hawks, are here in the first place, the optimum feeding conditions, showing almost all adaptive capacity to adjust to changing conditions.

Keywords: sparrowhawk; hawk; Samara city; city population; number; distribution; breeding; human impact; disturbance; current trends; manifestations of adaptation; atypical habitats; stable forage base; optimum conditions; limiting factors; adaptations; nesting success. 